\title{
Evaluation of the iPad as a low vision aid for improving reading ability
}

\author{
This article was published in the following Dove Press journal: \\ Clinical Ophthalmology \\ 19 December 2014 \\ Number of times this article has been viewed
}

\author{
Shamim A Haji \\ Kumar Sambhav \\ Sandeep Grover \\ Kakarla V Chalam \\ Department of Ophthalmology, \\ University of Florida College of \\ Medicine, Jacksonville, FL, USA
}

Correspondence: KV Chalam

Department of Ophthalmology, University of Florida College of Medicine, 580 W 8th Street, Tower 2, 3rd Floor, Jacksonville, FL, USA

Tel + I 904244936 I

Fax + I 9042449391

Email kchalam@jax.ufl.edu
Purpose: To evaluate the effect of the iPad as a low vision aid in improving the reading ability of low vision patients (LVPs).

Methods: In this study, 228 consecutive patients that came for their routine eye care examination at the University of Florida, Jacksonville eye clinic, were enrolled. Patients met inclusion criteria if they had best-corrected visual acuity (BCVA) of 20/100 or worse in the best corrected eye and were willing to participate in the study. The patient's reading ability was assessed both with the patient's own spectacles and an iPad. Patients were encouraged to enlarge the reading material as well as change the contrast until they could read comfortably. The number of patients able to read the text comfortably was recorded.

Results: Out of the total 228 participants who qualified, 103 (45\%) were male and $125(55 \%)$ were female. Only $22 \%$ could read standard newsprint-sized text (N8) without the help of an iPad. With the help of an iPad, 94\% participants with impaired vision were able to read standard newsprint-sized text (N8) or smaller text $(P<0.01)$.

Conclusion: The iPad, a new portable electronic media device, can be adapted by LVPs to improve their reading ability.

Keywords: low vision devices, low vision patient, LVP, iPad

\section{Introduction}

Low vision (reduction of functional vision) is often a consequence of decreased visual acuity, contrast sensitivity, and/or visual field loss. Age-related macular degeneration (AMD), glaucoma, and diabetic retinopathy are among the leading causes of low vision in the US. ${ }^{1}$ Reading ability is the most valued task among daily activities and has direct correlation with quality of life scores of low vision patients (LVPs). Analysis of reading performance is a useful tool in measuring the impact of visual disability and the success of recommended therapy. ${ }^{2}$

Traditional low vision aids often improve reading and are effective at helping the blind and partially sighted. Traditional options include hand-held reading addition, hand magnifiers, illuminated magnifiers, stand magnifiers, closed circuit television, and modified tools of daily living such as appliances with larger displays/buttons. While these tools are effective, they are cumbersome to use and are not user-friendly.

The iPad (Apple Inc., Cupertino, CA, USA), a touch-sensitive device, has built-in software that allows image magnification, contrast enhancement, and brightness modulation. The zoom feature offers magnification in levels up to five times (equivalent to a +20 D magnifier).

In this study, we evaluated the utility of the iPad as low vision aid in patients with poor vision. 


\section{Methods}

In this prospective institutional review board (IRB) approved nonrandomized observational study, 228 consecutive patients that came for their routine eye care examination at the University of Florida, Jacksonville eye clinic, were enrolled. Patients met inclusion criteria if they had best-corrected visual acuity (BCVA) of 20/100 or worse in the best corrected eye and were willing to participate in the study.

IRB/ethics committee (University of Florida College of Medicine IRB-3) approval was obtained. All research in this study complied with security, patient confidentiality, and the Health Insurance Portability and Accountability Act policy mandates. Informed written consent was obtained from all the participants.

Information about the participants' ocular condition, along with their age, sex, and visual acuity was recorded (Table 1). The reading ability of all the participants was assessed first with their reading glasses using a near vision chart. The initial percentage of reading ability with the reading glasses was assessed. Next, a text sample (size N8) from a preselected article in the New York Times viewed in the built-in Safari web browser (iPad) was used for each participant to assess reading ability. The Zoom feature offers full screen magnification in levels up to five times magnification (equivalent to a $+20 \mathrm{D}$ magnifier; Figure 1). Patients were encouraged to enlarge the reading material as well as change the contrast until they could read comfortably. The number of patients able to read the text comfortably was recorded.

The primary outcome was to assess the utility of the iPad in improving the reading ability of patients with poor vision.

\section{Results}

The demographic characteristics of the participants are summarized in Table 1. Out of the total 228 participants who qualified, 103 (45\%) were male and 125 (55\%) were females. Ages ranged from 58-92 years; the vast majority $(81 \%)$ were 60 years and older. Seventy-three $(32 \%)$ participants had AMD, 109 (48\%) had diabetic retinopathy, and $46(20 \%)$ had other vision conditions. One hundred and fifty-nine (70\%) participants had a diagnosis of hypertension.

The mean presenting best spectacle-corrected visual acuity (BSCVA) and reading vision for all the participants were 20/400 and N30, respectively. The median BSCVA and reading vision for the AMD group $(n=73)$, diabetic retinopathy group $(n=109)$, and others $(n=46)$ were $10 / 400$ and N30, 20/200 and N26, and 20/400 and N30, respectively.

With the assistance of the iPad, there was a marked increase in the number of participants who could read. Only 22\% could read standard newsprint-sized text (N8) without the help of the iPad. With the help of the iPad, 94\% participants with impaired vision were able to read standard newsprint-sized text $(\mathrm{N} 8)$ or smaller text $(P<0.01)$.

Table I Demographic and medical disease characteristics of the participants

\begin{tabular}{llll}
\hline Characteristics & Change in visual acuity & & Univariant P-values \\
\cline { 2 - 4 } & $\mathbf{N}$ & Percentage & 100 \\
\hline Total & 228 & 53 & 0.36 \\
Race & 120 & 47 & 0.36 \\
Non-white & 108 & & \\
White & & 55 & 0.90 \\
Sex & 125 & 45 & 0.90 \\
Women & 103 & & \\
Men & & 32 & 0.26 \\
Disease & 73 & 0.26 \\
Age-related macular degeneration & 109 & 48 & 0.26 \\
Diabetic retinopathy & 46 & 20 & \\
Others & & & \\
Age & 44 & 19 & $0.006 / 0.008$ \\
$<60$ years & 184 & 81 & $0.006 / 0.008$ \\
$\geq 60$ years & & & \\
Hypertension & 69 & 30 & 0.45 \\
No & 159 & 70 & 0.45 \\
Yes & & & \\
Change in visual acuity with iPad & 13 & 6 & 0.01 \\
No & 215 & 94 & 0.01 \\
Yes & & & \\
\hline
\end{tabular}


A
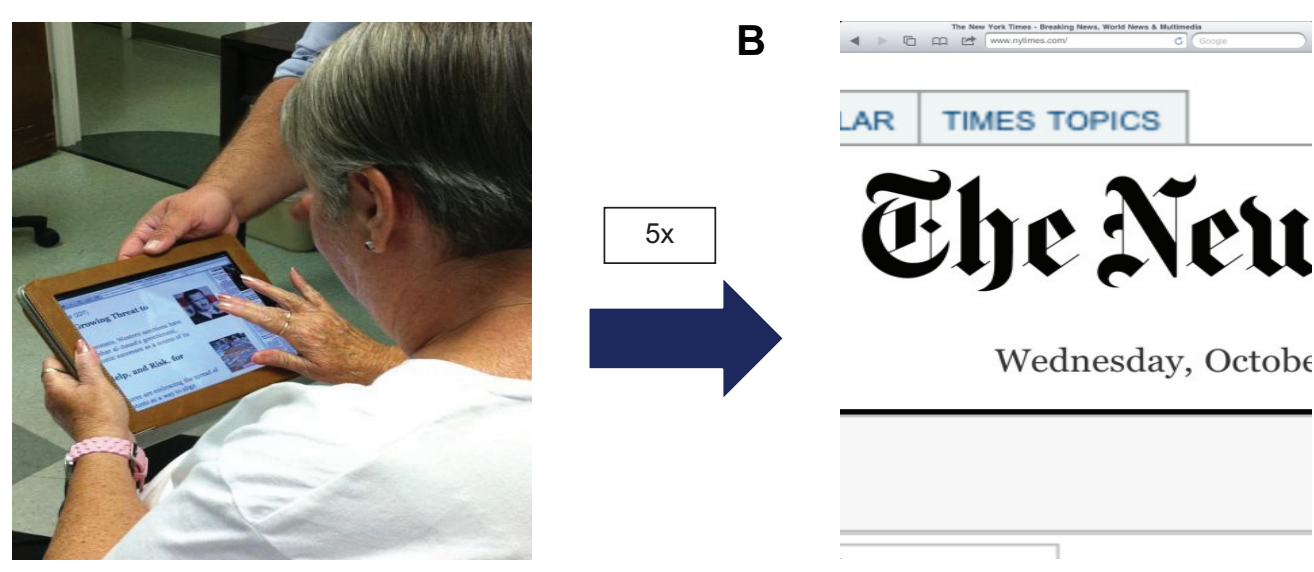

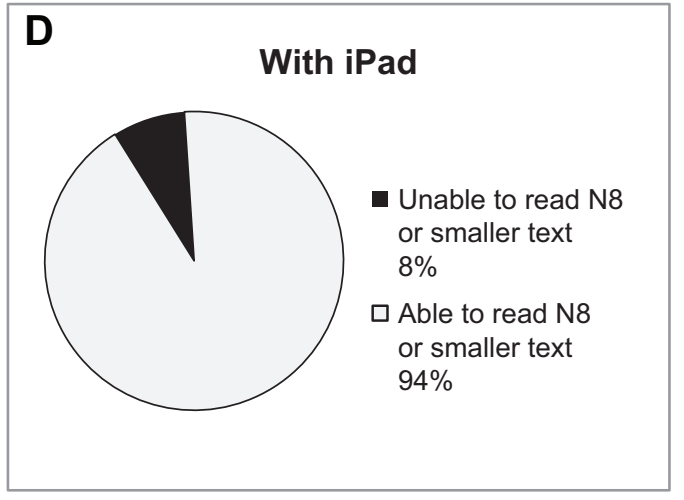

Figure I (A and B) Show patient using iPad without $(\mathbf{A})$ and with (B) $5 \times$ zoom function. (C and D) Pie charts depict the percentage of patients that could read at least N8 print without (C) and with (D) iPad.

Abbreviation: N8, standard newsprint-sized text.

Out of the total of 73 participants in the AMD group, 64 $(88 \%)$ could read N8 or smaller text $(P<0.01)$. Out of the total of 109 participants in the diabetic retinopathy group, 107 (98\%) could read N8 or smaller text $(P<0.01)$. Finally, out of the remaining 46 participants, $40(87 \%)$ could read N8 $(P<0.01)$ or smaller text.

\section{Discussion}

Low vision is a state of permanent impairment of vision that is not correctable with spectacles, contact lenses, or surgical intervention, and interferes with normal everyday functioning. Nearly 5 million Americans are affected to the extent that they are unable to read newsprint, even with the aid of spectacle correction. ${ }^{3,4}$ Many LVPs use electronic devices to read when traditional optical low vision aids fail. One of the electronic devices that has provided some benefit is the closed-circuit television (CCTV) system. They have been termed CCTVs due to the direct cable link between the camera-imaging system and monitorviewing system (in contrast to broadcast television), but this description generally refers to surveillance devices and does not indicate the provision of features, such as magnification and contrast enhancement, found in devices for the visually impaired. Therefore, the term electronic vision enhancement systems (EVES) was proposed by Wolffsohn and Peterson ${ }^{5}$ to better distinguish and describe such devices. EVES provides greater magnification than reading glasses, magnifiers, and microscopes. They also allow the user to adjust the size, brightness, and contrast of the magnified image to best match the user's vision. The user can even read white letters on a black background to decrease glare. However, prolonged sitting needed to use these devices results in neck pain and back ache, especially when using bifocals. Although EVES have been used in visual rehabilitation for over 30 years, they are extremely expensive and far less portable than current low vision aids available to LVPs.

Proliferation and miniaturization of consumer electronics in recent years have led to a new generation of more powerful and more portable gadgets for LVPs. 
There has been an explosion in the number and range of portable devices that patient with low vision can utilize. The iPad provides an alternative to low vision devices to assist LVPs. The tactile gestures to magnify or reduce text offer each patient an optimal atmosphere to improve reading ability and consequently improve the quality of life. The iPad is lightweight and mobile, with adjustable magnification, contrast, and brightness amenable to most patients. $^{6}$

The results of this study clearly show that the iPad is an effective method of improving reading ability in patients with low vision. In our study, $94 \%$ of patients were able to ready $\mathrm{N} 8$ or smaller newsprint in a predetermined article from the New York Times webpage. Gill et $\mathrm{al}^{7}$ in their recently published study, demonstrated that digital devices such as the Sony eReader and Apple iPad may have a use in visual rehabilitation for LVPs. However, compared to our study, many patients only had AMD in one eye, and were tested binocularly. In our study, all the patients had BCVA of $20 / 100$ or worse in both eyes.

In conclusion, the iPad, a new portable electronic media device, can be adapted by LVPs to improve their reading ability. Clinicians should consider portable electronic media devices as options for LVPs as alternatives or supplements to traditional tools.

\section{Acknowledgment}

This work was presented in part at the annual meeting of the American Academy of Ophthalmology, 2011; Orlando, FL, USA.

\section{Disclosure}

The authors report no conflicts of interest in this work.

\section{References}

1. Congdon N, O'Colmain B, Klaver CC, et al; Eye Diseases Prevalence Research Group. Causes and prevalence of visual impairment among adults in the United States. Arch Ophthalmol. 2004;122(4): 477-485.

2. Burggraaff MC, van Nispen RM, Hoeben FP, Knol DL, van Rens GH. Randomized controlled trial on the effects of training in the use of closed-circuit television on reading performance. Invest Ophthalmol Vis Sci. 2012;53(4):2142-2150.

3. Scott IU, Smiddy WE, Schiffman J, Feuer WJ, Pappas CJ. Quality of life of low-vision patients and the impact of low-vision services. Am J Ophthalmol. 1999;128(1):54-62.

4. Margrain TH. Helping blind and partially sighted people to read: the effectiveness of low vision aids. Br J Ophthalmol. 2000;84(8):919-921.

5. Wolffsohn JS, Peterson RC. A review of current knowledge on Electronic Vision Enhancement Systems for the visually impaired. Ophthalmic Physiol Opt. 2003;23(1):35-42.

6. Culham LE, Chabra A, Rubin GS. Users' subjective evaluation of electronic vision enhancement systems. Ophthal Physiol Opt. 2009; 29(2):138-149.

7. Gill K, Mao A, Powell AM, Sheidow T. Digital reader vs print media: the role of digital technology in reading accuracy in age-related macular degeneration. Eye (Lond). 2013;27(5):639-643.
Clinical Ophthalmology

\section{Publish your work in this journal}

Clinical Ophthalmology is an international, peer-reviewed journal covering all subspecialties within ophthalmology. Key topics include: Optometry; Visual science; Pharmacology and drug therapy in eye diseases; Basic Sciences; Primary and Secondary eye care; Patient Safety and Quality of Care Improvements. This journal is indexed on

Submit your manuscript here: http://www.dovepress.com/clinical-ophthalmology-journal
Dovepress

PubMed Central and CAS, and is the official journal of The Society of Clinical Ophthalmology (SCO). The manuscript management system is completely online and includes a very quick and fair peer-review system, which is all easy to use. Visit http://www.dovepress.com/ testimonials.php to read real quotes from published authors. 